\title{
Training-induced cognitive and neural plasticity
}

\section{Julia Karbach ${ }^{1 *}$ and Torsten Schubert ${ }^{2}$}

1 Department of Educational Science, Saarland University, Saarbruecken, Germany

2 Department of Psychology, Humboldt University, Berlin, Germany

${ }^{*}$ Correspondence: j.karbach@mx.uni-saarland.de

Edited by:

Hauke R. Heekeren, Freie Universität Berlin, Germany

Research on cognitive interventions and training-induced changes in brain and behavior has been of growing interest in cognitive neuroscience and related disciplines over the last decade (for reviews see Hertzog et al., 2008; Lustig et al., 2009; Shipstead et al., 2010; Morrison and Chein, 2011; for a recent meta-analysis see Melby-Lervåg and Hulme, 2013). The aim of this research topic is to provide a broad scope of state-of-the art research in order to advance the understanding of the scope and the mechanisms involved in cognitive and neural plasticity, that is, the potential modifiability of a person's cognitive abilities and brain activity.

Previous studies focusing on the magnitude and maintenance of training-related benefits have indicated that plasticity is considerable in healthy individuals across lifespan (e.g., Brehmer et al., 2007; Karbach and Kray, 2009; Karbach et al., 2010; Dorbath et al., 2011; Strobach et al., 2012a,c), and that it may even extend to very old age (Verhaeghen et al., 1992; Buschkuehl et al., 2008; Zinke et al., 2012b). Aside from training-related improvements on the trained task, researchers are especially interested in understanding the transferability of training-related performance gains to tasks that have not been part of the training. This issue is of particular importance for the application of training programs, e.g., in clinical and educational contexts, but also for the theoretical understanding of the processes underlying training and transfer effects. Recent evidence indicated that transfer effects might be enhanced if the training regime taps higher-level executive control processes instead of focusing on basic processing commodities or specific strategies (Lustig et al., 2009; Noack et al., 2009). Others showed that transfer of training can only occur if the training task and the transfer task engage overlapping cognitive processing components and brain regions (Dahlin et al., 2008). In addition, findings from behavioral cognitive training research have been accompanied by findings from cognitive neuroscience, indicating that cognitive training often induces practice-related changes in the neural substrate (for reviews see; Kelly and Garavan, 2005; Jones et al., 2006; Klingberg, 2010). These observations point to training-induced plasticity in several cortical and subcortical regions which can relate to neural changes within these regions as well as in networks of regions, emphasizing the importance of interdisciplinary approaches for investigating cognitive and neural changes after training.

The contributions of this research topic have addressed the nature, the scope and the preconditions of cognitive and neural plasticity from different angles. Two review articles provide an overview of recent findings on cognitive training in the areas of developmental psychology (Jolles and Crone, 2012) and cognitive aging (Buitenweg et al., 2012). Cognitive plasticity in childhood and in older age has also been addressed by several original research articles (Brehmer et al., 2012; Garrett et al., 2012; HannaPladdy and Gajewski, 2012; Kray et al., 2012; Lövdén et al., 2012; Lussier et al., 2012; Söderqvist et al., 2012; Strobach et al., 2012b; Zinke et al., 2012a). The findings reported in these publications provide strong evidence for the view that cognitive plasticity extends from childhood to older age (c.f. Brehmer et al., 2007; Karbach and Kray, 2009). Moreover, these results are supported by evidence indicting that cognitive plasticity is not only present in healthy individuals, but can also be found in patients suffering from developmental disorders (Kray et al., 2012), intellectual disability (Söderqvist et al., 2012), and chronic traumatic brain injury (Sacco et al., 2011).

In addition to investigating the effectiveness of cognitive training in different populations, such as different age groups or different types of patients, several contributions have also provided evidence for the usefulness of different training regimes. Most of these studies applied process-based training interventions, such as executive-control training (Kray et al., 2012; Lussier et al., 2012; Strobach et al., 2012b), working-memory training (Brehmer et al., 2012; Salminen et al., 2012; Schneiders et al., 2012; Söderqvist et al., 2012) or game training (Prakash et al., 2012; van Muijden et al., 2012), but also different types of physical training (Gajewski and Falkenstein, 2012; Zinke et al., 2012a,b). Nevertheless, it remains open which of these kinds of training most efficiently support the occurrence of transfer effects. Consistent with the growing interest in understanding the neural mechanisms underlying training-induced performance changes, a few of the studies have also applied neurophysiological (Gajewski and Falkenstein, 2012) und neuroimaging techniques (Sacco et al., 2011; Prakash et al., 2012; Schneiders et al., 2012), suggesting that training-induced behavioral changes were accompanied by significant changes in neural activity that varied as a function of the specific training intervention.

Recently, it has also been suggested to analyze training data from an individual differences perspective (see also Garrett et al., 2012). Addressing the question why some individuals benefit more than others from cognitive interventions is particularly important for the adaptation of training regimes to populations with specific needs. Two articles (Buitenweg et al., 2012; Jolles and Crone, 2012) have pointed to the importance of this aspect and Lövdén et al. (2012) have reported significant individual differences in memory training and transfer effects across the lifespan. However, a minimum cognitive capacity seems a necessary precondition for the manifestation of training and transfer effects (Söderqvist et al., 2012).

In sum, the current research topic provides a broad overview of new findings and contributes to a deeper understanding of 
cognitive and neural plasticity. It shows cognitive training to be a promising tool for investigating basic mechanisms of adaptive behavior and neuronal functioning as well as for designing training applications and interventions. The current findings have also pointed to a number of important topics and unsolved issues that

\section{REFERENCES}

Brehmer, Y., Li, S. C., Müller, V., von Oertzen, T., and Lindenberger, U. (2007). Memory plasticity across the life span: uncovering children's latent potential. Dev. Psychol. 43, 465-478.

Brehmer, Y., Westerberg, H., and Bäckman, L. (2012). Workingmemory training in younger and older adults: training gains, transfer, and maintenance. Front. Hum. Neurosci. 6:63. doi: 10.3389/fnhum.2012.00063

Buitenweg, J. I. V., Murre, J. M. J., and Ridderinkhof, K. R. (2012). Brain training in progress: a review of trainability in healthy seniors. Front. Hum. Neurosci. 6:183. doi: 10.3389/fnhum.2012.00183

Buschkuehl, M., Jaeggi, S. M., Hutchison, S., Perrig-Chiello, P., Däpp, C., Müller, M., et al. (2008). Impact of working memory training on memory performance in old-old adults. Psychol. Aging 23, 743-753.

Dahlin, E., Neely, A. S., Larsson, A., Bäckman, L., and Nyberg, L. (2008). Transfer of learning after updating training mediated by the striatum. Science 320, 1510-1512.

Dorbath, L., Hasselhorn, M., and Titz, C. (2011). Aging and executive functioning: a training study on focus-switching. Front. Psychol. 2:257. doi: 10.3389/fpsyg.2011.00257

Gajewski, P. D., and Falkenstein, M. (2012). Training-induced improvement of response selection and error detection in aging assessed by task switching: effects of cognitive, physical, and relaxation training. Front. Hum. Neurosci. 6:130. doi: 10.3389/fnhum.2012.00130

Garrett, D. D., MacDonald, S. W. S., and Craik, F. I. M. (2012). Intraindividual reaction time variability is malleable: feedbackand education-related reductions in variability with age. Front. Hum. Neurosci. 6:101. doi: 10.3389/fnhum. 2012.00101

Hanna-Pladdy, B., and Gajewski, B. (2012). Recent and past musical activity predicts cognitive aging variability: direct comparison with general lifestyle activities. Front. Hum. Neurosci. 6:198. doi: 10.3389/fnhum.2012.00198
Hertzog, C., Kramer, A. F., Wilson, R. S., and Lindenberger, U. (2008). Enrichment effects on adult cognitive development. Psychol. Sci. Public Interest 9, 1-65.

Jolles, D. D., and Crone, E. A. (2012). Training the developing brain: a neurocognitive perspective. Front. Hum. Neurosci. 6:76. doi: 10.3389/fnhum.2012.00076

Jones, S., Nyberg, L., Sandblom, J., Stigsdotter Neely, A., Ingvar, M., Petersson, K. M., et al. (2006). Cognitive and neural plasticity in aging: general and task-specific limitations. Neurosci. Behav. Rev. 30, 846-871.

Karbach, J., and Kray, J. (2009). How useful is executive control training? Age differences in near and far transfer of taskswitching training. Dev. Sci. 12, 978-990.

Karbach, J., Mang, S., and Kray, J. (2010). Transfer of task-switching training in older age: the role of verbal processes. Psychol. Aging 25, 677-683.

Kelly, A. M. C., and Garavan, H. (2005). Human functional neuroimaging of brain changes associated with practice. Cereb. Cortex 15, 1089-1102.

Klingberg, T. (2010). Training and plasticity of working memory. Trends Cogn. Sci. 14, 317-324.

Kray, J., Karbach, J., Haenig, S., and Freitag, C. (2012). Can task- switching training enhance executive control functioning in children with attention deficit/-hyperactivity disorder? Front. Hum. Neurosci. 5:180. doi: 10.3389/fnhum.2011.00180

Lövdén, M., Brehmer, Y., Li, S.-C., and Lindenberger, U. (2012). Traininginduced compensation versus magnification of individual differences in memory performance. Front. Hum. Neurosci. 6:141. doi: 10.3389/fnhum.2012.00141

Lussier, M., Gagnon, C., and Bherer, L. (2012). An investigation of response and stimulus modality transfer effects after dual-task training in younger and older. Front. Hum. Neurosci. 6:29. doi: 10.3389/fnhum.2012.00129

Lustig, C., Shah, P., Seidler, R., and Reuter-Lorenz, P. A. (2009). Aging, training, and the brain: a review and future directions. Neuropsychol. Rev. $19,504-522$.

will be relevant for forthcoming research: Among them questions regarding methodological approaches in training research, the mechanisms mediating the transfer of training-related benefits, and the usefulness of training for enhancing activities of daily living in different clinical and non-clinical populations.

Melby-Lervåg, M., and Hulme, C. (2013). Is working memory training effective? A meta-analytic review. Dev. Psychol. 49, 270-291.

Morrison, A. B., and Chein, J. M. (2011). Does working memory training work? The promise and challenges of enhancing cognition by training working memory. Psychon. Bull. Rev. 18, 46-60.

Noack, H., Lövdén, M., Schmiedek, F., and Lindenberger, U. (2009) Cognitive plasticity in adulthood and old age: gauging the generality of cognitive intervention effects. Restor. Neurol. Neurosci. 27, 435-453.

Prakash, R. S., De Leon, A. A., Mourany, L., Lee, H., Voss, M. W., Boot, W. R., et al. (2012). Examining neural correlates of skill acquisition in a complex videogame training program. Front. Hum. Neurosci. 6:115. doi 10.3389/fnhum.2012.00115

Sacco, K., Cauda, F., D'Agata, F. Duca, S., Zettin, M., Virgilio, R., et al. (2011). A combined robotic and cognitive training for locomotor rehabilitation: evidences of cerebral functional reorganization in two chronic traumatic brain injured patients. Front. Hum. Neurosci. 5:146. doi 10.3389/fnhum.2011.00146

Salminen, T., Strobach, T., and Schubert, T. (2012). On the impacts of working memory training on executive functioning. Front. Hum. Neurosci. 6:166. doi 10.3389/fnhum.2012.00166

Schneiders, J. A., Opitz, B., Tang, H., Deng, Y. A., Xie, C., Li, H., et al. (2012). The impact of auditory working memory training on the fronto-parietal working memory network. Front. Hum. Neurosci. 6:173. doi: 10.3389/fnhum.2012.00173

Shipstead, Z., Redick, T. S., and Engle, R. W. (2010). Does working memory training generalize? Psychol. Belgica 50, 245-276.

Söderqvist, S., Nutley, S. B., Ottersen, J., Grill, K. M., and Klingberg, T. (2012). Computerized training of non-verbal reasoning and working memory in children with intellectual disability. Front. Hum. Neurosci. 6:271. doi 10.3389/fnhum.2012.00271
Strobach, T., Frensch, P. A., Müller, H. J., and Schubert, T. (2012a) Age- and practice-related influences on dual- task costs and compensation mechanisms under optimal conditions for dual-task performance. Aging Neuropsychol. Cogn. 19, 222-247.

Strobach, T., Frensch, P., Müller, H. J., and Schubert, T. (2012b) Testing the limits of optimizing dual- task performance in younger and older adults. Front. Hum. Neurosci. 6:39. doi: 10.3389/fnhum.2012.00039

Strobach, T., Liepelt, R., Schubert, T., and Kiesel, A. (2012c). Task switching: effects of practice on switch and mixing costs. Psychol. Res. 76, 74-83.

van Muijden, J., Band, G. P. H., and Hommel, B. (2012). Online games training aging brains: limited transfer to cognitive control functions. Front. Hum. Neurosci. 6:221. doi: 10.3389/fnhum.2012.00221

Verhaeghen, P., Marcoen, A., and Goossens, L. (1992). Improving memory performance in the aged through mnemonic training: a meta-analytic study. Psychol. Aging 7, 242-251.

Zinke, K., Einert, M., Pfennig, L., and Kliegel, M. (2012a). Plasticity of executive control through task switching training in adolescents. Front. Hum. Neurosci. 6:41. doi: 10.3389/fnhum.2012.00041

Zinke, K., Zeintl, M., Eschen, A., Herzog, C andKliegel, M. (2012b). Potentials and limits of plasticity induced by working memory training in old-old age. Gerontology 58, 79-87.

Received: 31 January 2013; accepted: 05 February 2013; published online: 22 February 2013.

Citation: Karbach $J$ and Schubert $T$ (2013) Training-induced cognitive and neural plasticity. Front. Hum. Neurosci. 7:48. doi: 10.3389/fnhum.2013.00048 Copyright (c) 2013 Karbach and Schubert. This is an open-access article distributed under the terms of the Creative Commons Attribution License, which permits use, distribution and reproduction in other forums, provided the original authors and source are credited and subject to any copyright notices concerning any third-party graphics etc. 